\title{
QUALIDADE E APRESENTAÇÃO DE SALADAS SERVIDAS NA ROTISSERIA DE UMA REDE DE SUPERMERCADOS
}

\section{QUALITY SALADS SERVED ON A NETWORK OF ROTISSERIA SUPERMARKETS}

\author{
Noeli Cararo ${ }^{1}$; Tiffany Prokopp Hautrive ${ }^{2}$; \\ ${ }^{1,2}$ Universidade Comunitária da Região de Chapecó - UNOCHAPECÓ - Chapecó - Brasil \\ ${ }^{2}$ Universidade Federal de Santa Maria - UFSM - Santa Maria - Brasil - tiffanyhautrive@yahoo.com.br
}

\begin{abstract}
Resumo
Objetivou-se avaliar a qualidade de saladas servidas na rotisseria de uma rede de supermercados. Este estudo foi realizado em duas lojas de uma rede de supermercados da cidade de Chapecó - SC representados por " $A$ " $e$ " $B$ ". Por meio de listas de verificação e observação nos locais, foi avaliada a higienização dos utensílios, móveis e manipuladores, a higienização das saladas, a temperatura de exposição das saladas no bufê da rotisseria e a apresentação das saladas no bufê (tipos de cortes e decoração, diversidade e presença de folhosos, entre outros). Os resultados quanto à qualidade higiênico-sanitária apresentaram que o supermercado " $A$ " demonstra $60 \%$ de não conformidade na higienização dos utensílios, móveis e manipuladores, enquanto que o " $B$ " apresenta 40\%. Em relação à higienização das saladas, o supermercado " $A$ " apresentou 100\% de não conformidade, enquanto que o " $B$ " apresentou $0 \%$. A temperatura média no bufê das saladas estava em $14,37^{\circ} \mathrm{C}$ no supermercado " $B$ " e 9,42 ${ }^{\circ} \mathrm{C}$ no supermercado " $A$ ". Na apresentação das saladas no bufê observou-se que no supermercado " $A$ " a beterraba e a cenoura aparecem em $100 \%$ dos dias cortadas em forma de rodelas e no supermercado " $B$ " a beterraba aparece com $60 \%$ dos dias com corte juliana. Verificou-se que as saladas não estão sendo preparadas de forma adequada quanto à qualidade higiênico-sanitária e que a apresentação e decoração dos pratos de saladas estão muito repetitivos.
\end{abstract}

Palavras-chave: supermercados; hortaliças; qualidade; higiene; rotisseria.

\section{Introdução}

Qualquer alimento comercializado deve, por legislação, ser armazenado e processado em condições que garantam a qualidade higiênico-sanitária, bem como manter suas características organolépticas. Esta qualidade passou a ser considerada a chave para o sucesso em qualquer ramo de atividade como forma de manter-se em níveis de competitividade. O consumidor tem se mostrado mais atento e consciente ao adquirir um produto, exigindo qualidade no preparo, na composição e no valor nutricional do alimento (RAMOS et al., 2004). 
De acordo com Martins (2006) a microbiologia é fator essencial na avaliação da qualidade dos alimentos processados, sendo necessário considerar as consequências de todas as práticas da produção, desde o processamento, armazenamento e na distribuição desses produtos, estabelecendo os riscos para contaminação por patógenos passíveis de causar danos à saúde do consumidor.

Para Saccol (2007) a contaminação pode ocorrer na área de produção, durante todo o processamento e a contaminação microbiológica é conhecida como a mais ameaçadora à saúde humana, pois os mais frequentes casos de contaminação são causados por microrganismos patogênicos. A sobrevivência desses microrganismos nos alimentos decorre principalmente, das condições inadequadas de higiene e de temperatura em que esses alimentos são expostos durante o processamento, armazenamento e distribuição dos mesmos.

Para Silva Jr. (2001) os alimentos podem ser contaminados através do contato com utensílios, superfícies e equipamentos não higienizados corretamente. Para evitar a contaminação, devemos deixar o ambiente impróprio para o ataque de microrganismos, não deixando os alimentos expostos em temperatura ambiente por períodos prolongados; promover a higienização ambiental e dos utensílios, ou seja, mesas de trabalho, tábuas de corte, facas, vasilhas, deverão estar corretamente higienizados (MOREIRA et al., 2007)

A matéria-prima de origem vegetal está sujeita a diversas fontes de contaminação microbiana ao longo do seu cultivo e processamento, desde a água da irrigação, até os manipuladores, o solo, os equipamentos, os utensílios e o preparo destes, necessitando de estratégias por parte das empresas produtoras, objetivando garantir da qualidade desses alimentos (CRUZ, CENCI e MAIA, 2006).

As hortaliças, particularmente as consumidas cruas, podem servir como via de transmissão de parasitas intestinais ao homem, uma vez que cistos de protozoários, ovos e larvas de helmintos podem nelas estar presentes. Nesse contexto, sobressai a importância de medidas preventivas capazes de levar à erradicação desses agentes contaminantes nos alimentos, já que na maioria das vezes faltam ao consumidor informações sobre a qualidade da hortaliça disponível comercialmente (SOARES, 2006).

De acordo com Takayanagui et al. (2001), esse meio de transmissão de várias doenças infecciosas e parasitárias mostra-nos a necessidade de ações básicas para o desenvolvimento das boas práticas de manipulação destas verduras em todas as etapas do processamento e distribuição.

A correta higienização e armazenagem dos alimentos visam à proteção destes contra contaminação, inibindo a multiplicação dos microorganismos bem como a destruição dos microorganismos patogênicos (SACCOL, 2007).

Todo tipo de gênero alimentício destinado à comercialização, deve satisfazer as exigências quanto à qualidade, possuir valor nutricional adequado e boa aparência, além de boas condições de 
higiene e sanidade na preparação e no armazenamento. Quando os alimentos não apresentam condições higiênico-sanitárias adequadas, podem ocasionar problema ao comensal, como as doenças veiculadas por alimentos, e também para a empresa processadora, como por exemplo, problemas de ordem econômica e de imagem (FURLANETO e CORRÊA, 2006).

A garantia de satisfação dos comensais clientes e a manutenção destes parece estarem envolvidas com todo o processo de produção. A inadequada forma de preparo dos alimentos pode trazer riscos tanto para a saúde dos comensais quanto problema para a empresa responsável pela produção. Diante desse contexto, o objetivo desta pesquisa é avaliar a qualidade higiênico-sanitária e apresentação das saladas servidas na rotisseria de duas lojas de uma rede de supermercados de Chapecó - SC.

\section{Material e Métodos}

Este trabalho foi realizado em duas lojas de uma rede de supermercados da cidade de Chapecó - SC, sendo que, uma loja está situada no centro do município e outra em um bairro da cidade. As lojas serão mencionadas em Supermercado A e Supermercado B.

\section{Qualidade higiênico-sanitária}

Para avaliar a qualidade higiênico-sanitária das saladas servidas na rotisseria destes supermercados foram elaboradas e aplicadas listas de verificação em cada loja da rede de supermercado, verificando se os procedimentos de higiene realizados estavam em conformidade com as legislações brasileiras. Foram analisados os procedimentos de higiene e desinfecção das bancadas e utensílios da área de preparo das saladas, com detergente e álcool 70\%, a utilização pelos manipuladores de uniforme limpo e adequado e a constante lavagem de mãos pelos manipuladores no início do trabalho, a cada troca de alimento e atividade. Na higienização das saladas foram analisados os procedimentos de lavagem das hortaliças em água corrente, desinfecção com solução clorada, diluição correta do desinfetante, tempo de permanência da hortaliça no desinfetante e enxágue em água corrente.

\section{Análise de temperatura}

Foi avaliada a temperatura em que as saladas permaneceram expostas no bufê da rotisseria dos supermercados. Foram analisadas a temperatura do bufê da rotisseria e a temperatura de 10 tipos diferentes de saladas durante 4 dias consecutivos.

Os instrumentos para coleta da temperatura foram um termômetro digital específico para alimentos do tipo espeto, marca Incoterm, com variação de $-50{ }^{\circ} \mathrm{C}$ a $300{ }^{\circ} \mathrm{C}$, papel toalha e álcool 
70\% para higienização do mesmo. A análise dos dados da temperatura foi através de Programa Estatístico SAS versão 6.11, com médias que diferem significativamente entre si pelo teste de Tukey a 5\% de significância.

A Portaria ${ }^{\circ} 06$ CVS do estado de São Paulo, Brasil, de 10 de março de 1999, relata que os alimentos frios, devem ser mantidos abaixo de $10^{\circ} \mathrm{C}$ até o momento da distribuição, quando distribuídos a esta temperatura devem ficar expostos por até 4 horas ou de $10^{\circ} \mathrm{C}$ a $21^{\circ} \mathrm{C}$ por até 2 horas. Estas temperaturas são medidas no centro geométrico dos alimentos sendo que as preparações que ultrapassarem os prazos estipulados devem ser desprezadas (BRASIL, 1999).

A Resolução 216 da Agência Nacional de Vigilância Sanitária, Brasil, de 15 de setembro de 2004, não refere sobre a temperatura que devem estar os alimentos frios como saladas e sobremesas. Portanto, foi utilizado como parâmetro de temperatura ideal para as saladas as contidas na Portaria CVS 06/1999.

\section{Apresentação e decoração das saladas no bufê}

A análise da apresentação e decoração das saladas foi realizada de forma visual no momento do preparo das saladas pelas colaboradoras e na distribuição no bufê da rotisseria. Verificou-se os tipos de cortes e decoração realizados com as hortaliças, o uso de condimentos como tempero, a diversidade das saladas, presença de folhosos, saladas cozidas e cruas, presença de grãos e salada de maionese.

\section{Capacitação em serviço}

A partir dos resultados coletados foi desenvolvida uma capacitação em serviço com as colaboradoras responsáveis pelo preparo das saladas, abordando a forma correta de higienização das saladas, higienização dos utensílios e móveis, condutas higiênicas dos colaboradores, tempo e temperatura adequada para conservação das saladas e qualidades sensoriais das saladas.

Após a capacitação com os colaboradores foi aplicado novamente as listas de verificação sobre os aspectos higiênicos-sanitários e a coleta de temperatura com o objetivo de avaliar os resultados antes e após a capacitação e intervenções.

\section{Resultados e Discussão}

O quadro 1 demonstra o percentual de conformidade para a higienização dos utensílios, móveis, manipuladores e saladas. A higienização dos utensílios, móveis e manipuladores no supermercado "A" está 60\% não conforme e 40\% conforme e no supermercado "B", $60 \%$ conforme e $40 \%$ não conforme. As não-conformidades estão em relação à não utilização do álcool $70 \%$ para a desinfecção e a frequência inadequada da lavagem de mãos pelos manipuladores. 
$\mathrm{Na}$ avaliação da higienização das saladas, observou-se que no supermercado "A" apresentou $100 \%$ de não conformidade, já o supermercado "B" apresentou $100 \%$ em conformidade. O supermercado "A" não está realizando de forma adequada a desinfecção das hortaliças.

$\mathrm{Na}$ reavaliação após a capacitação em serviço com os colaboradores da rotisseria foi encontrado $100 \%$ de conformidade nos dois supermercados tanto para a higiene dos utensílios, móveis e manipuladores quanto para a higienização das saladas, demonstrando ótimo resultado. Entretanto, este resultado significativo, tem de diminuir no decorrer dos dias caso não houver supervisão pela chefia e constantes capacitações com a equipe.

Quadro 1- Percentual de conformidade para higiene dos utensílios, móveis, manipuladores e saladas, em uma rede de supermercados, Chapecó-SC.

\begin{tabular}{|ccc|}
\hline Procedimentos & Antes capacitação & Após capacitação \\
\hline Higiene dos utensílios, móveis e manipuladores & & \\
Supermercado A & & \\
Supermercado B & $40 \%$ conforme & $100 \%$ conforme \\
& $60 \%$ conforme & $100 \%$ conforme \\
Higienização das saladas & & \\
Supermercado A & & $100 \%$ conforme \\
Supermercado B & $0 \%$ conforme & $100 \%$ conforme \\
\hline
\end{tabular}

A higiene dos alimentos se caracteriza por processos pelos quais os alimentos se tornam higienicamente e sanitariamente adequados para o consumo, utilizando-se para tanto técnicas e produtos para limpeza e desinfecção de alimentos e também dos materiais utilizados na preparação dos mesmos (SILVA JR, 2001).

Sabe-se da importância em se avaliar as condições higiênico-sanitárias de alimentos como controle de qualidade, pois segundo Furlaneto e Corrêa (2006), somente a inspeção do produto final como atividade de controle de qualidade não agrega valor, pois ao se detectar nessa fase que o produto se encontra fora dos requisitos estabelecidos, nada pode ser feito para correção deste processo, necessitando sim, de atividades de controle preventivas, durante a preparação dos mesmos.

Para a Portaria CVS-06/99, a higiene de hortifrutigranjeiros compreende: lavagem criteriosa com água potável, desinfecção através de imersão em solução clorada por 15 a 30 minutos e enxágue com água potável.

Os utensílios, recipientes e instrumentos de trabalho deverão ser mantidos em perfeitas condições de higiene, mediante frequentes lavagens com água corrente e descontaminação com 
água fervente ou solução desinfetante apropriada (PORTARIA No 1288, de 27 de Novembro de 1995).

Quanto à higiene pessoal o manipulador deve cumprir, diariamente, os seguintes hábitos de higiene: barba feita, bigode aparado e cabelos totalmente protegidos; unhas curtas, limpas, sem esmalte ou base, sem maquiagem; é vedada a utilização de adornos como, colar, amuleto, pulseira, fita, brinco, relógio e anel, aliança, e inclusive piercing, que possa representar risco de contaminação. O mesmo deve lavar as mãos sempre que iniciar ou trocar de atividade, utilizar sanitários, tossir espirrar ou assoar o nariz; tocar em alimentos não higienizados ou crus, entre outras (PORTARIA n ${ }^{\circ} 2.535$, de 24 de Outubro de 2003).

Soto et al. (2008), descreve que as irregularidades sanitárias detectadas em seu estudo estão relacionadas com higiene na manipulação dos alimentos, uniformes e higiene pessoal inadequada, apenas $6,89 \%$ dos estabelecimentos pesquisados apresentaram níveis satisfatórios no quesito higiene.

Gomes et al. (2008), analisou o percentual de conformidades das condições higiênicosanitárias em vários estabelecimentos comerciais, apresentou índice de conformidade de $40 \%$ dos itens analisados.

Comparando os resultados encontrados antes da capacitação dos colaboradores neste trabalho com dos autores citados, percebe-se grande semelhança nos resultados, ou seja, a qualidade higiênico-sanitária ainda é deficiente nos estabelecimentos produtores de refeições.

A tabela 1 apresenta as temperaturas do bufê e das saladas nos supermercados "A"e "B". O bufê apresentou uma temperatura média de $8,47^{\circ} \mathrm{C}$ para o supermercado " $\mathrm{A}$ ” e $18,37^{\circ} \mathrm{C}$ no supermercado "B". Pode-se observar que as temperaturas das saladas foram maiores no Supermercado "B" quando comparados com o Supermercado "A". A temperatura das saladas no Supermercado "A" variou de $8,27^{\circ} \mathrm{C}$ a $11,10^{\circ} \mathrm{C}$ e no Supermercado "B" entre $13,40^{\circ} \mathrm{C}$ a $17,87^{\circ} \mathrm{C}$.

Tabela 1- Média das temperaturas $\left({ }^{\circ} \mathrm{C}\right)$ das saladas nos supermercados “A"e "B", antes da capacitação, em uma rede de supermercados de Chapecó-SC.

\begin{tabular}{ccc}
\hline Bufê e Saladas & Supermercado "A" & Supermercado "B" \\
\hline Bufê da rotisseria & $8,47 \pm 0,34$ & $18,37 \pm 2,31$ \\
Rúcula & $9,22 \pm 0,57$ & $17,15 \pm 0,73$ \\
Alface americana & $8,27 \pm 1,03$ & $14,52 \pm 3,17$ \\
Repolho & $9,37 \pm 1,35$ & $13,83 \pm 2,09$ \\
Broto alfafa/feijão & $11,10 \pm 1,95$ & $14,45 \pm 0,31$ \\
Tomate & $9,42 \pm 1,43$ & $13,40 \pm 0,80$ \\
Ovos & $10,27 \pm 0,46$ & $17,87 \pm 0,84$ \\
Cenoura cozida & $9,02 \pm 1,30$ & $13,42 \pm 2,33$ \\
Beterraba cozida & $8,35 \pm 1,21$ & $14,60 \pm 1,72$ \\
Grãos & $9,65 \pm 0,90$ & $13,72 \pm 0,66$ \\
Maionese & $9,42 \pm 1,28$ & $14,37 \pm 2,43$ \\
\hline
\end{tabular}

Valores expressos em media \pm desvio padrão. $n=4$ 
$\mathrm{Na}$ capacitação com os colaboradores foi enfatizada a importância de ligar os balcões térmicos antes de colocar as saladas no bufê, objetivando melhorar a temperatura do mesmo, bem como não colocar as saladas cozidas quentes no bufê. Com a implantação dessas medidas, obteve-se uma redução da temperatura do bufê e das saladas servidas, conforme demonstra a tabela 2.

O binômio tempo x temperatura é um fator muito importante para produzir refeições com qualidade, serva para, eliminar ou diminuir o número de microrganismos, durante o processamento, manipulação e distribuição dos alimentos para consumo (SILVA JR, 2001).

Segundo Silva Jr. (2001): Alimentos frios são potencialmente perigosos favorecendo uma rápida multiplicação microbiana. Deverão ser distribuídos no máximo a $10{ }^{\circ} \mathrm{C}$ por até 4 horas; quando a temperatura estiver entre $10{ }^{\circ} \mathrm{C}$ e $21{ }^{\circ} \mathrm{C}$, só poderão permanecer na distribuição por 2 horas; alimentos que ficaram na distribuição mais que 4 horas até $10^{\circ} \mathrm{C}$ ou mais que 2 horas entre $10{ }^{\circ} \mathrm{C}$ e $21{ }^{\circ} \mathrm{C}$ ou que estiveram acima de $21^{\circ} \mathrm{C}$ devem ser desprezados.

Silva Jr. (2001), ainda recomenda temperatura especial para algumas saladas, como saladas à base de maionese (industrializada) devem ser expostas no bufê em temperaturas de até de $4{ }^{\circ} \mathrm{C}$. Saladas de grãos, ovos e legumes cozidos, deve-se observar rigorosamente a temperatura de apresentação no bufê (até $4{ }^{\circ} \mathrm{C}$ ) e tempo de exposição em temperatura de risco não superior a 30 minutos.

Tabela 2- Média das temperaturas $\left({ }^{\circ} \mathrm{C}\right)$ nos supermercados “A”e "B”, após a capacitação, em uma rede de supermercados de Chapecó-SC.

\begin{tabular}{ccc}
\hline Bufê e Saladas & Supermercado "A" & Supermercado "B” \\
\hline Bufê da rotisseria & $8,27 \pm 0,87$ & $6,62 \pm 0,92$ \\
Rúcula & $8,62 \pm 0,97$ & $7,92 \pm 1,56$ \\
Alface americana & $8,05 \pm 0,71$ & $8,17 \pm 1,01$ \\
Repolho & $8,27 \pm 0,87$ & $6,62 \pm 0,92$ \\
Broto alfafa/feijão & $8,87 \pm 1,17$ & $6,87 \pm 2,00$ \\
Tomate & $8,42 \pm 1,01$ & $6,83 \pm 0,36$ \\
Ovos & $8,82 \pm 0,79$ & $6,95 \pm 0,75$ \\
Cenoura cozida & $8,62 \pm 1,89$ & $7,52 \pm 0,71$ \\
Beterraba cozida & $7,90 \pm 0,87$ & $5,65 \pm 1,51$ \\
Grãos & $8,05 \pm 1,03$ & $6,70 \pm 1,79$ \\
Maionese & $8,92 \pm 0,65$ & $5,07 \pm 1,78$ \\
\hline
\end{tabular}

Valores expressos em media \pm desvio padrão. $n=4$

Temperaturas ideais para a rápida proliferação microbiana pode representar um fator de risco importante nos episódios de toxiinfecções alimentares, não permitindo garantir a segurança das preparações oferecidas aos comensais (STORCK et al., 2003).

As recomendações vigentes especificam que preparações frias devem ser mantidas a $10{ }^{\circ} \mathrm{C}$ por 4 horas, ou de 10 a $21{ }^{\circ} \mathrm{C}$ por no máximo 2 horas, sendo essas as condições adequadas para garantir a segurança do produto (ABERC, 2000; PORTARIA CVS-6/99). 
$\mathrm{Na}$ avaliação da apresentação e decoração das saladas servidas na rotisseria do supermercado "A", observou-se que os tipos de cortes das saladas eram repetitivos e com poucas variedades. A beterraba e a cenoura aparecem em 100\% dos dias cortadas da mesma forma, ou seja, em rodelas, o tomate com $60 \%$ dos dias cortado de forma igual. Nenhuma salada foi preparada com os cortes juliana e jardineira.

O supermercado "B", também apresentou pouca diversidade de cortes, sendo que, a beterraba aparece com $60 \%$ das vezes cortada em forma de rodelas e $20 \%$ em forma de brunoise. O chuchu e a cenoura aparecem com $60 \%$ dos dias com corte igual, em forma de Juliana e o tipo de corte jardineira nunca foi encontrado.

Quanto à utilização do uso de condimentos, observou-se que no supermercado "B" o uso de condimentos quase nunca era utilizado.

$\mathrm{Na}$ avaliação quanto à presença de saladas coloridas os dois supermercados " $\mathrm{A}$ " e "B", apresentaram presença de cinco e quatro cores, respectivamente.

Para a diversidade das saladas, avaliou-se a presença de folhosos, saladas cozidas, saladas cruas, presença de grãos e maionese. A presença destes itens é preconizada pela direção da empresa, como presença obrigatória nas saladas servidas pelas rotisserias diariamente. Sendo que no supermercado "A", são preparados o total 18 tipos de saladas e no supermercado "B", 10 tipos.

A Tabela 4 demonstra a apresentação e decoração das saladas servidas na rotisseria antes e após a capacitação.

Tabela 4: Apresentação e decoração das saladas servidas na rotisseria em uma rede de supermercados de Chapecó-

SC/Brasil.

\begin{tabular}{ccccc}
\hline & Supermercado A & & \multicolumn{2}{c}{ Supermercado B } \\
& Antes da & Após & Antes da & Após \\
& capacitação & capacitação & capacitação & Capacitação \\
\hline Beterraba e cenoura & $100 \%$ em rodelas & Rodelas, paisana, juliana & $60 \%$ rodelas & Paisana e brunoise \\
Corte jardineira & Nunca & 2 dias $(50 \%)$ & Nunca & Nunca \\
Corte juliana & Nunca & 3 dias $(75 \%)$ & 3 dias $(75 \%)$ & 3 dias $(75 \%)$ \\
Cond. shoyu & 5 saladas p/dia & 2 saladas p/ dia & Nunca & Nunca \\
Cond. tom. seco & 4 saladas p/dia & 2 saladas p/ dia & 1 dia & 1 dia \\
Folhosos & 4 tipos & 5 tipos & 2 tipos & 3 tipos \\
Presença Grãos & 2 dias & Todos os dias & 3 dias & 3 dias \\
Diversid. cores & 5 cores & 5 cores & 4 cores & 6 cores \\
Decoração igual & 8 pratos & 3 pratos & 3 pratos & Nenhum igual \\
\hline
\end{tabular}

Diante dos resultados obtidos, verificou-se a necessidade de padronização quanto à forma de preparo e os tipos de saladas que deverão compor o cardápio diariamente. O quadro 2 refere a padronização realizada para as saladas para o supermercado "A" e "B". 
Quadro 1- Padronização das saladas para o supermercado "A" e "B", em uma rede de supermercados de ChapecóSC/Brasil.

\begin{tabular}{|ccc|}
\hline SALADAS & $\begin{array}{c}\text { Supermercado “A” } \\
\mathbf{1 8} \text { tipos diariamente }\end{array}$ & $\begin{array}{c}\text { Supermercado "B" } \\
\mathbf{1 0} \text { tipos diariamente }\end{array}$ \\
\hline $\begin{array}{c}\text { FOLHOSOS - alface, agrião, rúcula, radicci, } \\
\text { almeirão, indívia, acelga, couve folha, chicória, } \\
\text { radicci vermelho. }\end{array}$ & $\mathbf{4}$ tipos ao dia & 3 tipos ao dia \\
\hline $\begin{array}{c}\text { SALADAS COZIDAS - abobrinha, brócolis, } \\
\text { vagem, chuchu, couve-flor, cenoura, beterraba. }\end{array}$ & 5 tipos ao dia & 2 tipos ao dia \\
\hline $\begin{array}{c}\text { SALADAS CRUAS - repolho, pimentão, cenoura, } \\
\text { beterraba, nabo, rabanete, broto de alfafa e feijão, } \\
\text { pepino, cebola, tomate, conservas. }\end{array}$ & 6 tipos ao dia & 3 tipos ao dia \\
\hline Grãos - feijão de diversos tipos, grão-de-bico, soja, & 1 tipo ao dia & 1 tipo/2x por semana \\
\hline trigo para quibe & & Todo dia \\
\hline Maionese de batata & Todo dia & 1 tipo/2x por semana \\
\hline Salpicão ou maionese doce (manga, abacaxi, maçã, & 1 tipo ao dia & \\
\hline uvas passas) ou macarronese &
\end{tabular}

Para Proença et al. (2005), as cores das saladas, a composição e as misturas são essenciais aos aspectos visuais, atraindo a atenção dos comensais ao desejo em consumir este alimento.

Produtos como qualquer fruta ou hortaliça, ou ainda qualquer combinação delas, independente do tipo, é selecionado, lavado, descascado e cortado, resultando num produto $100 \%$ aproveitável, devem apresentar atributos de qualidade, como o frescor, aroma, cor e sabor mantendo o máximo de suas características nutritivas e sensoriais (DE PAULA, 2009).

Qualidades sensoriais, como cheiro, cor, textura, sabor e aparência são fatores determinantes nas escolhas alimentares dos indivíduos, contribuindo para a ingestão, saciedade e escolhas dos alimentos em uma refeição (RIEKES, 2004).

Cardoso e Boekel (2005) avaliaram a satisfação do consumir no quesito: corte das saladas, saladas cruas e coloridas, encontraram; dos 63 entrevistados, 94\% estavam acostumados e gostavam de consumir hortaliças cruas em saladas, $70 \%$ gostaram da alface cortada em tiras e quanto a disposição das cores, agradou a 95\% dos entrevistados.

\section{Conclusão}

O resultado desta pesquisa demonstra que as saladas não estão sendo preparadas com $100 \%$ de conformidade quanto à qualidade higiênico-sanitária como prevê a legislação brasileira. Além disso, verificou-se a monotonia e repetição no uso de cortes, decoração de pratos e pouca diversidade nas cores durante o preparo das saladas. 
A partir dos resultados encontrados, acredita-se ser importante a implantação de medidas que possam melhorar o cuidado na manipulação durante a preparação das saladas, pois, após a capacitação observou-se melhora significativa em vários aspectos, como principalmente, conformidade da higiene pessoal, higienização das saladas e higienização das bancadas e utensílios.

\begin{abstract}
The objective was to evaluate the sanitary quality of sensory and salads served at the deli of a supermarket chain. This study was conducted in two stores of a supermarket chain of Chapeco - SC Brazil, represented by " $A$ " and " $B$ ". Through checklists and observation sites, we evaluated the cleanliness of utensils, furniture and handlers, the hygiene of the salads, the temperature exposure of salads on the buffet of deli salads and sensory quality (types of cuts and decorations, diversity and presence of stalks, etc.). The results regarding the hygienic quality showed that the supermarket "A" shows $60 \%$ of non-compliance in the cleanliness of utensils, furniture and handlers, while the " $B$ " has 40\%. Regarding the hygiene of salads, supermarket "A" had 100\% noncompliance, while the " $B$ " had $0 \%$. The average temperature in the buffet of salads was $14.37^{\circ} C$ in the supermarket " $B$ " and $9.42^{\circ} C$ in the supermarket " $A$ ". In the sensory evaluation showed that in the supermarket " $A$ " turnips and carrots appear in $100 \%$ of days cut into slices at the supermarket and " $B$ " appears beets with $60 \%$ of days with julienne cut. It was found that the salads are not being properly prepared on the hygienic quality and the presentation and decoration of dishes from salads are very repetitive.
\end{abstract}

Key-words: Supermarkets; vegetables; sanitary quality; sensory.

\title{
Referências
}

ABERC - Associação Brasileira das Empresas de Refeições Coletivas. Manual ABERC de Práticas de Elaboração e Serviços de Refeições para Coletividades. 6 ed. São Paulo: 2000.

CARDOSO, M. H.; BOEKEL, S. V. Avaliação Sensorial de Salada de Verão: Estudo do Efeito do Tipo de Corte de Hortaliças Cruas sobre a Preferência do Consumidor. Revista de Nutrição, v. 18, n. 5 , p. 670 , set./out. 2005.

DE PAULA, N. R. F. Qualidade de produtos minimamente processados e comercializados em gôndolas de supermercados nas cidades de Lavras - MG, Brasília - DF e São Paulo - SP. Ciência e Agrotecnologia. v. 33, n. 1, jan./fev. 2009.

FURlaneto, L.; CORRÊA, D. S. Avaliação Microbiológica de Componentes de Pratos Árabes. Universidade Estadual de Londrina - UEL, Departamento de Microbiologia da Saúde e Universidade Norte do Paraná - UNOPAR. Londrina - PR: 2006. Disponível em: http://www.uepg.br. Acesso em: 26 de abr. 2011.

GOMES, L. C. S. Higiene para manipuladores de alimentos em estabelecimentos. Produtores /manipuladores de alimentos na cidade de Bananeiras - PB. Disponível em:http://www.prac.ufpb.br/anais/xenex_xienid/x_enex/ANAIS/Area5/5CFTDTRPEX01.pdf. Acesso em: 01 de mai. 2011.

MARTINS, F. O. Avaliação da qualidade higiênico-sanitária de preparações (sushi e sashimi) a base de pescado cru servidas em bufês na cidade de São Paulo. Faculdade de Saúde Pública (FSP), 2006. Disponível em: http://www.teses.usp.br. Acesso em: 01 mai. 2011. 
MORAIS, F. A. et al. Perdas de Vitamina C em Hortaliças Durante o Armazenamento, Preparo e Distribuição em Restaurantes. Ciência \& Saúde Coletiva para a Sociedade, 2007. Disponível em: http://www.abrasco.org.br/cienciaesaudecoletiva. Acesso em 01 mai. 2011.

MOREIRA, S. et al. Análise de coliformes fecais em utensílios e manipuladores no laboratório de nutrição de uma faculdade particular de Cascavel. Disponível em: www.controlare.com.br/erp/open/midia_detalhe.asp?cng_ukey=39832151701B0HN1KR. Acesso em: 06 de jun. 2011

PORTARIA CVS-6/99, DE 10.03.99. Regulamento Técnico, que estabelece os Parâmetros e Critérios para o Controle Higiênico-Sanitário em Estabelecimentos de Alimentos. Secretaria de Estado de Saúde, São Paulo - SP.

PORTARIA No 1288, DE 27 DE NOVEMBRO DE 1995. Normas técnicas elaboradas pela Superintendência de Vigilância Sanitária objetivando regulamentar a comercialização de alimentos no estado de Goiás. Secretário de Estado da Saúde, Goiás - Goiânia.

PORTARIA SMS. G No 2.535, DE 24 DE OUTUBRO DE 2003. LEGISLAÇÃO MUNICIPAL. Regulamento Técnico para o controle higiênico-sanitário em empresas de alimentos/bebidas. O Secretário Municipal da Saúde, São Paulo - SP.

PROENÇA, R. P. C. et al. Qualidade Nutricional e Sensorial na Produção de Refeições. Florianópolis: Ed. da UFSC, 2005.

RAMOS, N. P. et al. Qualidade Higiênico-Sanitária de 10 Amostras de Polpa de Açaí Congelada Fabricada por uma Indústria do Município de João Pessoa - PB. Centro de Tecnologia / Departamento de Tecnologia de Química e de Alimentos da Universidade Federal da Paraíba, 2004. Disponível em: http://www.prac.ufpb.br. Acesso em: Acesso em: 01 mai. 2011.

RIEKES, B. H. Qualidades em Unidades de Alimentação e Nutrição: uma proposta metodológica considerando aspectos nutricionais e sensoriais. 2004. $171 \mathrm{f}$. Dissertação (Mestrado em Nutrição) - Universidade Federal de Santa Catarina, Florianópolis - SC, 2004.

RIBEIRO, C. S. G. R. Análise de perdas em unidades de alimentação e nutrição (UANs) industriais: estudo de caso em Restaurantes Industriais. 2003. 145p. Dissertação (Mestrado em Engenharia de Produção) - Universidade Federal de Santa Catarina, Florianópolis, 2003.

RODRIGUES, S.; MARTINS, A. H. Avaliação da Estrutura Física em Unidades de Alimentação e Nutrição da Cidade de Cascavel - PR. Departamento de alimentação e Nutrição da Faculdade Assis Gurgacz - FAG, Cascavel - PR, 2004. Disponível em: www.fag.edu.br. Acesso em: 01 de mai. 2011.

SACCOL, A. L. F. Sistematização de Ferramenta de Apoio para Boas Práticas em Serviço de Alimentação. 2007. 188 f. Dissertação (Mestrado em Ciência e Tecnologia dos Alimentos) Universidade Federal de Santa Maria, Santa Maria - RS, 2007.

SILVA JR. E. A. Manual de Controle Higiênico-Sanitário em Alimentos. $4^{\text {a }}$ ed. São Paulo: Livraria Varela, 2001.

SOARES, B. Avaliação de Agentes Químicos Indicados para Descontaminação de Hortaliças. Saúde em Revista, v. 8, n.19, p. 45-49, 2006. 
SOTO, F. R. M. et al. Metodologia de avaliação das condições sanitárias de vendedores ambulantes de alimentos no Município de Ibiúna-SP. Revista Brasileira de Epidemiologia, v. 11, n. 2, São Paulo, 2008.

SOUSA, C. L.; CAMPOS, G. D. Condições higiênico-sanitárias de uma dieta hospitalar. Revista de Nutrição, v. 16, n. 1, jan./mar. 2003. http://dx.doi.org/10.1590/S1415-52732003000100013.

STORCK, C. R. et al. Monitoramento da temperatura de Preparações Quente e Frias em Restaurantes Self-Service, na zona urbana de Santa Maria. Revista Nutrição em Pauta, n. 59, 2003.

TAKAYANAGUI, O. M. et al. Fiscalização de verduras comercializadas no município de Ribeirão Preto, SP. Revista da Sociedade Brasileira de Medicina Tropical, v.4, n.1, p. 37-41, jan-fev, 2001.

Submetido em 08 dez. 2011, Aceito para publicação em 21 dez. 2012. 